\title{
Leigos na linha de frente? Uma reflexão a respeito do laicato no atual momento evangelizador
}

\author{
Lay people on the front line? \\ A reflection about the laity in the current \\ evangelizing moment
}

Joel Portella Amado

\section{Resumo}

Com a aprovação do documento a respeito do laicato, a Conferência dos Bispos do Brasil buscou acelerar o processo de resposta evangelizadora aos desafios do mundo e da Igreja dos dias atuais. Estes desafios dizem respeito ao reconhecimento dos leigos e leigas como sujeitos eclesiais, expressão que dá título ao documento. Tal condição exige que se reflita sobre a antropologia e a eclesiologia necessárias ao reconhecimento da condição de sujeito, condição essa distinta da apresentada pela modernidade. Vários são os desafios práticos, de modo especial aqueles que se referem ao lugar da ação dos leigos, se no mundo e também na Igreja.

Palavras-chave: Laicato. Sujeito eclesial. Eclesiologia de comunhão.

\section{Abstract}

With the approval of the document concerning the laity, the Conference of Bishops of Brazil purposed to accelerate the process of evangelizing response to the challenges of the world and the Church of today. These challenges relate to the recognition of lay men and women as ecclesial subjects, expression that 
gives title to the document. This condition requires us to reflect on anthropology and ecclesiology able to recognize the subject condition, distinct from the subjectivity presented by modernity. There are several practical challenges, especially those that refer to the place of laity's action in the world and inside the Church.

Keywords: Laity. Ecclesial subject. Ecclesiology of communion.

\section{Introdução}

A Conferência dos Bispos do Brasil aprovou na Assembleia Geral de 2016 um documento a respeito do laicato. Este foi o tema central da Assembleia, com o sugestivo título "Cristãos leigos e leigas na Igreja e na sociedade-Sal da terra e luz do mundo". A publicação recebeu o número 105, dentro do conjunto de textos oficiais da Conferência Episcopal Brasileira, passando, em consequência, a ser conhecida como Documento 105 (DOC 105). O texto percorreu longo processo de produção, indo e vindo, entre a comissão que cuidou de sua elaboração e as dioceses. ${ }^{1}$ Recebeu tempo maior para maturação quando comparado a outros documentos e, agora, depois de aprovado, chega à Igreja no Brasil, para que, apropriado pelas comunidades, de modo especial pelo próprio laicato, produza os frutos desejados. Aqui se pretende fazer uma reflexão pastoral sobre o tema dos leigos e leigas no atual momento da Igreja, como mais uma ajuda para o acolhimento e a implementação das propostas do Documento dos Bispos. Não deseja ser um recolhimento do já estudado em outros lugares acerca da temática do laicato, embora, em alguns pontos, vá repetir não apenas o Documento, mas também o que se tem em termos de reflexão mais recente sobre o tema. A base sobre a qual se reflete é o que se convencionou chamar de nova evangelização e o patamar para a teologia do laicato é o Concílio Vaticano II, em especial nos âmbitos da antropologia teológica e da eclesiologia.

\section{O laicato sob a ótica da Nova Evangelização}

Sobre a Nova Evangelização muito já se falou. Nos últimos tempos,

\footnotetext{
${ }^{1} \mathrm{O}$ documento começou a ser preparado por uma comissão que o apresentou na $52^{\mathrm{a}}$ Assembleia Geral da CNBB, em 2014, tendo recebido a aprovação para que continuasse a ser um texto de estudo. Foi então publicado na Série Estudos, sob o número 107. Obteve aprovação na $54^{\mathrm{a}}$ Assembleia, em 2016.
} 
dentro da rapidez cronológica com que tudo é consumido em nossos dias, esta expressão já não tem, na prática, recebido o destaque de antes, sendo até mesmo substituída por outras, como, por exemplo, igreja em missão, igreja em campanha ou igreja samaritana. $O$ fato, porém, de não se referir a um termo não significa que a realidade por ele aludida tenha sido superada. Ao contrário, algumas vezes, passa-se apenas para uma nova etapa semântica, permanecendo, entretanto, a problemática com toda a sua força. Na verdade, entre a expressão escolhida para esta reflexão e as demais, existe inegável correlação, na medida em que umas explicam, ampliam ou detalham as outras. Sobre a história do termo nova evangelização, com suas incidências e problemáticas, muito já se escreveu e nestas fontes se poderá encontrar farto material para aprofundamento. ${ }^{2}$ Aqui, importa centrar o foco nos motivos pelos quais se optou por manter semanticamente como nova evangelização e sua relação com o destaque dado ao laicato.

Nesse sentido, uma das formas mais acessíveis de se compreender o que subjaz ao termo nova evangelização consiste em estabelecer correlação direta com outro termo também bastante utilizado nas últimas décadas. Trata-se da expressão mudança de época. Entre esses dois termos existe direta vinculação, a qual não pode ser esquecida, seja qual for o projeto evangelizador que se queira construir. Os dois termos se referem a um mundo onde o cristianismo experimenta externamente o deslocamento da posição hegemônica e internamente a pluralidade nas compreensões e nas formas de agir. De fato, uma ação evangelizadora acostumada à plausibilidade sociocultural, isto é, a ser a organizadora da realidade e a possuir pouca margem de variação no seu modo de existir e agir, assusta-se quando se percebe em meio a uma gama de outras possibilidades religiosas, com suas respectivas consequências humanas e sociais, diversidade essa atuando inclusive internamente. Se, em outros momentos da história da evangelização no Brasil, a presença católica experimentou a preeminência, atualmente contempla o surgimento de diversas outras propostas religiosas, algumas com a pretensão de hegemonia e, consequentemente, trazendo o desafio a respeito do que fazer.

\footnotetext{
${ }^{2}$ FISICHELLA, R. La Nuova Evangelizzazione. Una sfida per uscire dall'indifereza. Padova: Mondatori, 2011; FISICHELLA, R. "La nueva evangelización a la luz del Magisterio Pontificio”. In: PONTIFICIA COMISIÓN PARA AMERICA LATINA. Reflexiones sobre la nueva evangelización em América Latina. Desafios y Prioridades. Vaticano: CAL, 2012, pp. 15-30; DUQUE, A. D. La nueva evangelización. Itinerario, Identidad y Características a partir del Magisterio Episcopal Latinoamericano. Bogotá: CELAM, 2012.
} 
Internamente, o cristianismo experimenta a emersão de formas diversificadas de viver a fé. Algumas dessas formas se manifestam mais identificadas com as contemporâneas tendências religiosas transconfessionais, enquanto outras se apresentam mais voltadas para um passado que as jovens gerações cronologicamente não experimentaram. Nos dois casos, o que se percebe é a busca por uma identidade sociocultural, colocando a questão não tanto no campo especificamente teológico, porém muito mais no campo existencial e pastoral. Isso acontece porque as referências sociais e culturais adequadas por séculos já não o são atualmente.

Estes fatos tão presentes no cotidiano de nossas comunidades ajudam a compreender o período atual da história da ação evangelizadora exatamente como uma mudança de época. Nestas, os parâmetros mais profundos, que fornecem identidade a tudo que existe, não encontram fôlego sociocultural para cumprir sua função. $O$ que antes servia como explicação já não serve mais. Valores, critérios e fundamentos entram em crise, no sentido mais autêntico da palavra, isto é, necessitam de recompreensão e rearrumação na escala de prioridades. Não estamos numa etapa em que as transformações são grandes apenas na quantidade, não atingindo, entretanto, os critérios de compreensão do real. Estamos numa etapa da história da humanidade em que não só as transformações são realmente incontáveis, mas também e acima de tudo, abalam os critérios de compreensão da totalidade da vida. Tal situação leva à passagem do plausível para o tateável. Por plausível, se compreende a presença sólida dos fundamentos, facilmente encontrados nas tradições e instituições. Por tateável, se compreende um processo de contínua busca, sem muitas certezas a respeito do que se encontra.

Este fato atinge o cristianismo e, nele, o catolicismo de modo bastante direto. Ainda que as leituras da história possam ser diferentes, a experiência cristã católica no Brasil se construiu a partir da presença do catolicismo como a religião da maioria, a religião do brasileiro. Embora sempre presentes, as demais religiões, com suas respectivas propostas de sentido para a vida, eram vistas como exceções. A questão aqui, no entanto, não consiste na comparação entre o papel das diversas religiões na formação da identidade brasileira. Reside no efeito desta realidade sobre o modo de ser cristão católico. Enquanto religião predominante, os efeitos assumem um rosto. Ao emergir a mudança de época, os efeitos são outros. Nos períodos históricos de predominância, seja do catolicismo seja de qualquer outra religião, quem tem a predominância tem a proteção das tradições e instituições, tornando-se o caminho usual de 
adesão. A maioria tende a seguir o majoritário. Nas mudanças de épocas, a perda maior consiste exatamente nesta plausibilidade, isto é, na condição de ser um caminho socioculturalmente lógico, em que não se exigem grandes explicações para sua aceitação. Nestes momentos históricos, a ação pastoral consiste na manutenção ou conservação, ${ }^{3}$ com a predominância da moral e dos sacramentos. Quando, porém, se ingressa num período de mudança de época histórica, a situação se alterna diametralmente, pois desaparece a plausibilidade sociocultural, surgindo inúmeras possibilidades e inúmeras formas de busca e encontro das referências, das plausibilidades.

O problema que as mudanças de época trazem para o catolicismo é o da alteração de sua forma de presença no todo social. Já não se trata mais de se considerar como socioculturalmente lógico, porém de participar, ao lado de todas as demais propostas, do embate pelo sentido da existência. Este embate, por certo, poderá assumir a forma de guerra santa, com todas as possibilidades aqui incluídas, desde a violência ostensiva, como se assiste em alguns lugares do mundo, até a formação de alianças, grupos de influência ou bancadas políticas. Outro caminho é o da reconfiguração na compreensão e na prática da missão. E neste segundo caminho que se insere a nova evangelização. $\mathrm{Na}$ medida em que o catolicismo já não pode mais se utilizar com a mesma tranquilidade das bases socioculturais alicerçadas nas tradições e instituições, pressupondo-se como o caminho lógico para as escolhas pessoais, o caminho é o da reapresentação de si mesmo, caminho que pode ser feito a partir do embate, ao estilo das guerras santas, ou a partir da missão, onde se reconfiguram as prioridades e se explicitam aspectos que antes estavam implícitos, porque considerados enraizados na consciência religiosa das pessoas.

Já em 2007, os bispos da América Latina e do Caribe se voltavam para este problema na Conferência de Aparecida. Ao ingressarmos na primeira década de apropriação e implantação das conclusões da Conferência de Aparecida, é sugestivo que se recorde a lucidez do diagnóstico e das proposições daquele encontro. Aparecida pode ser compreendida como a afirmação oficial da Igreja latino-americana e caribenha de que as instituições transmissoras

\footnotetext{
${ }^{3}$ Embora utilizados no cotidiano pastoral para se referirem às atividades que envolvem apenas as mesmas pessoas sem perspectiva missionária, estes dois termos, quando compreendidos tecnicamente, referem-se mais à ação pastoral que considera realizado o encontro com a pessoa e a mensagem de Jesus Cristo em decorrência da sociedade e da cultura serem cristãs. Neste caso, a transmissão da fé acontece pelas famílias e demais instituições, cabendo à ação pastoral manter o que já existe e ela o faz primordialmente pela moral e pelos sacramentos.
} 
dos valores e da fé já não conseguem mais fazê-lo com o mesmo vigor de antes (DAp 38), sendo, por conseguinte, necessário abandonar as estruturas ultrapassadas que já não favoreçam mais a transmissão da fé (DAp 65). Daí a proposta de recomeçar a partir de Jesus Cristo, sem dar coisa alguma por descontada (DAp 12, 41 e 549). Este núcleo das conclusões de Aparecida vem sendo assumido pelo Papa Francisco, de modo especial em sua Exortação Apostólica Evangelii Gaudium, considerada como a base para o que o atual Papa compreende e deseja a respeito da ação evangelizadora da Igreja. Aquelas indicações que, sob o pontificado de João Paulo II, se firmaram com o nome de nova evangelização, no ardor, nos métodos e nas expressões, têm vivenciado um processo de amadurecimento com o aumento da clareza quanto à sua importância no discernimento do que se deve considerar como prioritário.

De modo resumido, é possível dizer que, diante das mudanças de época, o caminho é a nova evangelização. Estes dois conceitos estão diretamente ligados. Diante da perda da plausibilidade sociocultural, em que a ação evangelizadora se concentra muito mais nos sacramentos e na moral, o caminho é o da apresentação existencial da pessoa e da mensagem de Jesus Cristo. Não se abandona, por certo, a ação voltada para os sacramentos e a moral, mas já não se pode mais considerar que a base sobre a qual ambos são anunciados e vivenciados, isto é, a adesão a Jesus Cristo e ao Reino de Deus, possua níveis de tranquilidade sociocultural como em outros momentos da história. $\mathrm{O}$ que em outros momentos é presumido, nas mudanças de época deve necessariamente ser explicitado.

Ora, sacramentos e moral tendem a ser muito mais ligados ao clero. O laicato tende a ser muito mais o receptor destas duas dimensões. Tendo recebido a fé através do pais e da família, o cristão leigo ou leiga se apresenta para firmar sua adesão através dos sacramentos e receber ajuda para viver de modo condizente, ou seja, em termos de moral. Quando, porém, exatamente nas mudanças de época, se trata de dar as razões da convicção, o peso sociocultural do laicato aumenta bastante. A importância do clero se enfraquece enquanto brota de uma instituição, no caso, a instituição Igreja Católica. Num processo de forte individualização, o clero adquire plausibilidade muito mais a partir do testemunho pessoal do que de sua condição institucional. No atual momento da história religiosa do Brasil, as pessoas não seguem um clérigo predominantemente pelo fato de ele ser clérigo, mas pelo fato de ele ser um clérigo diferenciado, isto é, com a capacidade carismática de chegar até a vida de cada um(a). De certo modo, a vinculação muito direta com uma 
instituição, num tempo em que a dimensão institucional anda em baixa, coloca a condição de clero em desvantagem sociocultural. Ao contrário, o laicato, que, nos momentos de maior plausibilidade institucional e tradicional, não é visto como personagem relevante para a transmissão e a vivência da fé, assume papel preponderante. Mudanças de época e nova evangelização são momentos, portanto, para o laicato. São momentos do laicato. Por isso, o Doc. 105 afirma claramente que, "mais que no passado, temos hoje as condições eclesiais, as condições sociais, políticas e culturais e as bases eclesiológicas para que o cristão leigo exerça sua missão como autêntico sujeito eclesial, apto a atuar na Igreja e na sociedade e a promover uma relação construtiva entre ambas" (122).

\section{Uma questão que não é apenas histórica}

O fato de se dizer que as mudanças de época e a proposta de nova evangelização são momentos propícios ou próprios para o laicato pode ser compreendido erradamente, no sentido de que, ultrapassada a mudança, tudo voltará ao que era antes. Por isso, é tão importante refletir sobre a teologia do laicato que brota do Concílio Vaticano II, para que se pergunte se a atual relevância evangelizadora do laicato é somente um momento histórico ou se pode ser caracterizada como a recuperação de aspectos importantes da identidade cristã. Aqui também, como se disse a respeito da nova evangelização, existe farta literatura sobre a questão do laicato no Concílio Vaticano II. ${ }^{4}$ Importa recolher os aspectos mais importantes e verificar como se articulam com as dinâmicas da mudança de época e da nova evangelização.

Dito de modo bastante simples, a eclesiologia anterior ao Vaticano II considerava a existência de dois tipos distintos de cristãos. De um lado, estavam os clérigos e os religiosos e, de outro, os leigos. Aos primeiros, cabia preponderantemente a atividade espiritual. Aos demais, a ação no âmbito temporal. Esta diferenciação, por sua vez, repousava sobre outra ainda mais importante, a saber, a diferença entre Igreja e mundo. Tamanha a importância

\footnotetext{
${ }^{4}$ Por exemplo: MILITELlO, C. (Coord.). Os leigos depois do Concílio. A identidade e a missão dos cristãos. Prior Velho: Paulinas, 2012; ASTIGUETA, D. G. La noción de laico desde el Concilio Vaticano II al CIC 83. El laico: sacramento de la Iglesia y del mundo. Roma: Gregoriana, 1999; NAVARRO, L; PUIG, F. (Cur). Il fedele laico. Realtà e prospettive. Milano: Giuffre, 2012; PINHEIRO, J. E.; ALVES, A. A. Os cristãos leigos no mundo da política à luz do Concílio Vaticano II. Petrópolis: Vozes, 2013.
} 
desta concepção diferenciada que o Código de Direito Canônico de 1917 a transformou em princípio normativo, afirmando no cânon 107 que, por divina instituição, há na Igreja os clérigos distintos dos leigos (grifo nosso). Esta perspectiva não desconsidera a dignidade laical, mas a concebe em chave de distinção e subordinação em relação ao clero, ${ }^{5}$ isto por extensão da mesma perspectiva na relação entre Igreja e mundo, bem como na relação entre o sobrenatural e o natural. Vista muito mais como instituição e sociedade perfeita, definida a partir da existência de uma hierarquia, a Igreja se compreendia, em consequência, muito mais a partir do clero, responsável pelos meios de salvação, isto é, o culto e a guarda doutrinal. A importância da ação laical não era obviamente negada. Era, no entanto, subordinada, numa lógica em que o superior conduz, orienta e indica caminhos. ${ }^{6}$ Por isso, os leigos deveriam, como se falava naquele período, sustentar as pias sociedades de culto e devoção espiritual.

$\mathrm{O}$ século $\mathrm{XX}$, com todas as mudanças que trouxe e o consequente avançar do processo secularizador, acelerou a crise neste tipo de concepção baseada muito mais na distinção e na subordinação. Para se permanecer restrito ao campo do laicato, a gradativa transformação levou-o a sair da condição de subordinado sustentador das pias sociedades à função de agente em meio à sociedade, em vista de preservar e difundir os valores cristãos. Cresceu, portanto, o papel ativo dos leigos e leigas e sua responsabilidade na missão da Igreja. O problema maior sempre foi o de um substrato teórico capaz de sustentar esta transformação, pois a eclesiologia construída em base de oposição e subordinação, por mais que pudesse ser alargada, não trazia em si condições para o salto que estava sendo dado. Um exemplo é a Encíclica Mystici Corporis, do Papa Pio XII, promulgada em 1943. Neste documento importante para a compreensão da história da teologia do laicato, o Papa sintetizou o pensamento da época, com as dificuldades decorrentes das novas situações, mantendo, no entanto, a base eclesiológica da distinção ou oposição e subordinação. ${ }^{7}$ A partir de uma teoria teológica

\footnotetext{
${ }^{5}$ Cf. ZANETTI, E. La nozione di laico nel dibattito preconciliare. Alle radici di una svolta significativa e problemática. Roma: PUG, 1998, especialmente pp. 19-76.

${ }^{6}$ Cf. ANTON, A. "Lo sviluppo della dotrina sulla Chiesa nella teologia dal Vaticano I al Vaticano II". In: ANTON, A. L'ecclesiologia dal Vaticano I al Vaticano II. Bréscia: La Scuola, 1973, pp. 27-86.

${ }^{7}$ Cf. TURBANTI, G. "A autonomia dos leigos da Lumen Gentium à Gaudium et Spes”. In: MILITELlO, C. (Coord). Os leigos depois do Concílio. A identidade e a missão dos cristãos. Lisboa: Paulinas, 2012, pp. 12-13.
} 
em que predomine a distinção, adquire força o pensamento de que a atuação dos leigos tem seu campo no mundo, nas atividades temporais ou seculares. Não se fecha, nesta perspectiva, a participação dos leigos na vida interna da Igreja. O destaque, entretanto, é atribuído ao agir dos leigos no mundo exatamente por estes ali se encontrarem, em vista de o santificar, realizando os valores do Reino de Deus. ${ }^{8}$

A questão se manteve oficialmente deste modo até o Vaticano II. Era preciso encontrar categorias que permitissem articular as diversidades de maneira diferente da até então concebida. No cotidiano da vida das igrejas, o laicato caminhava na missão. Um exemplo relevante é a ação católica, com tudo que ela significou. Em termos especificamente teológicos, existiram também diversas contribuições, dentre as quais é preciso destacar a de Yves Congar, o qual, não apenas com a reflexão sob os três múnus (ensinar, governar e celebrar), mas acima de tudo com a aplicação dos mesmos a todos os fiéis, abriu portas importantes para que se superasse a dicotomia até então predominante. ${ }^{9}$ Existe a diferença, mas esta não precisa ser pensada em chave de oposição e exclusão. Ao contrário, a dicotomia é superada através da perspectiva da comunhão e este acabou sendo o núcleo da eclesiologia conciliar conforme manifestado na Lumen Gentium, principalmente a partir da categoria de Povo de Deus, ${ }^{10}$ em que se afirmam os laços teológicos de reciprocidade entre todos os membros deste Povo. Consequentemente, sai fortalecida a responsabilidade eclesial do laicato, conforme se pode perceber no capítulo $4^{\circ}$ da referida Constituição. Na linha do que aqui está sendo refletido, destacam-se os números 32 , sobre a dignidade dos leigos enquanto membros do Povo de Deus, e 34 a 36, nos termos do tríplice múnus, conforme indicava Congar.

A questão do pensamento relacional de algum modo já se encontra, portanto, resolvida em termos teológicos. ${ }^{11} \mathrm{O}$ problema permanece, no entanto,

\footnotetext{
${ }^{8}$ Obras clássicas deste período são: CHENU, M. D. Pour une théologie du travail. Paris: Seuil, 1955; DANIÉLOU, J. Essai sur le mystère de l'histoire. Paris: Seuil, 1953.

${ }^{9}$ CONGAR, Y. Jalons pour une théologie du laicat. Paris: Cerf, 1953.

${ }^{10}$ Texto clássico para a história do Concílio, onde se pode conseguir reflexão mais detalhada sobre a virada eclesiológica do Vaticano II é ALBERIGO, G. Storia del Concilio Vaticano II. Bologna: Peeters, Leuven \& Il Mulino, 2012. Trata-se de uma nova edição atualizada e ampliada.

${ }^{11}$ Cf. AMADO, J. P. "Realmente livres? A ambiguidade antropológica dos ambientes urbanos". In: RUBIO, A. G. O humano integrado. Abordagens de antropologia teológica. Petrópolis: Vozes, 2007, pp. 23-46, especialmente pp. 37-44.
} 
no cotidiano de pessoas e comunidades, uma vez que o pensar em chave de oposição acaba sendo mais forte. Isso acontece por razões cronológicas, isto é, por ter sido o predominante por muito tempo. Ocorre também pela flacidez das identidades, tão própria das mudanças de época e geradora de apegos ao que se conhece. Diante dessa resistência prática da lógica da oposição, há de se reiterar a riqueza da eclesiologia do Vaticano II e sua perspectiva comunional, conforme, por exemplo, aparece no Código de Direito Canônico de 1983, onde, antes de se afirmarem as diferenças, afirma-se a vera aequalitas, verdadeira igualdade, no que diz respeito à dignidade e à ação comum na edificação do Corpo de Cristo (LG 32). ${ }^{12}$

E, pois, a partir desta categoria de comunhão que também se deve compreender o que a Gaudium et Spes indica ao se referir ao laicato. Buscando articular as dimensões natural e sobrenatural da realidade, esta Constituição tira consequências para o laicato na medida em que analisa as relações da Igreja com o mundo moderno. Ao mesmo tempo que afirma o caráter irrenunciável da perspectiva salvífico-escatológica, a GS não nega o valor próprio da ação na cidade terrena, na história da humanidade. Tal relação se dá a partir de um prisma antropológico bem específico, qual seja, o indicado no famoso $\mathrm{n}^{\mathrm{o}} 22 \mathrm{da}$ GS, em que se afirma que o mistério do ser humano só se revela plenamente no mistério de Cristo, Verbo Encarnado. Trata-se, portanto, de uma missão de serviço, de sal, luz e fermento, no dizer bíblico, escolhido como título do Documento da Conferência dos Bispos do Brasil. Em postura de contínuo diálogo, a Igreja, respeitando a autonomia das realidades terrestres, apresenta diuturnamente o mistério de Jesus Cristo e do Reino de Deus para iluminar as alegrias e as esperanças do ser humano de cada tempo e lugar.

O laicato torna-se, em consequência, impulsionado a atuar em todas as realidades históricas, uma vez que ficam rejeitadas as tendências ao fechamento em torno exclusivamente do sobrenatural ou espiritual (GS 43). Ao mesmo tempo em que, atuando individualmente, os leigos são impelidos a adquirirem perícia nos variados campos da realidade terrestre, devem sempre fazê-lo à luz de Jesus Cristo. O critério da consciência individual formada adquire importância na ação do laicato, a ponto de se poder dizer que representa "o horizonte mais vasto de autonomia que o Concílio reconhece aos leigos e à sua atuação". ${ }^{13}$

${ }^{12}$ Cf. KASPER, W. Theologie und Kirche. Mainz: Matthias-Grünewald-Verlag, 1987, p. 285.

${ }^{13}$ TURBANTI, G. "A autonomia dos leigos da Lumen Gentium à Gaudium et Spes". In: MILITELLO, C. (Coord). Os leigos depois do Concílio. A identidade e a missão dos cristãos. Prior Velho: Paulinas, 2012, p. 45. 
Por tudo isso, há de se concluir que a atuação do laicato junto ao mundo, fortalecida nos períodos históricos de mudança de época, como o atual, não constitui somente uma estratégia sazonal, a ser abandonada em um futuro acento da poeira. Ao contrário, a mudança de época, com o consequente desafio da nova evangelização, ajuda de modo significativo a colocar em prática uma realidade que a consciência da Igreja no Vaticano II já afirmava. No dizer do documento recém-publicado, trata-se de compreender os cristãos leigos e leigas como sujeitos eclesiais, explicitando a partir daí sua ação no mundo e na Igreja.

\section{A condição de sujeito eclesial}

Como o próprio documento indica (DOC 105, 1), a expressão sujeito eclesial foi recolhida do Documento de Aparecida (DAp 497a) e "fundamentada nos ensinamentos do Concílio Vaticano II e do Magistério subsequente" (DOC 105, 10). Refere-se à corresponsabilidade do laicato na missão evangelizadora compreendida, nos termos do próprio documento, dentro do horizonte da nova evangelização (DOC 105, 2), com a abertura de espaços de participação, protagonismo e corresponsabilidade (DOC 105, 3). O tema é diretamente tratado no capítulo terceiro do Documento, que apresenta como título a expressão sujeito eclesial, com a explicitação "discípulos missionários e cidadãos do mundo" (DOC 105, 91ss) e com detalhamento no item 3 do referido capítulo (DOC 105, 119). Já na abertura do capítulo, algumas características desta condição de sujeito são apresentadas: consciência da dignidade, liberdade, responsabilidade, bem como capacidade de optar e decidir. Todas estas características são sempre direcionadas para uma vida de doação ao serviço do Reino de Deus, num amor incondicional (DOC 105, 91). A dignidade do ser humano como sujeito encontra seu fundamento na teologia da criação, conforme a compreende a experiência judaico-cristã (DOC 105, 121) e este é o ponto de distinção entre diferentes formas de se compreender a condição de sujeito.

De fato, o termo sujeito é, na prática, mais compreendido a partir do conteúdo que a modernidade lhe atribuiu, ou seja, a partir de sua individualidade como condição primordial. A subjetividade moderna não deixou de afirmar outras características do ser humano, dentre as quais a relacionalidade. A primazia, entretanto, acabou por ser dada à individualidade egocentrada, para a qual a relacionalidade não é uma condição constitutiva, mas sim consequente, 
podendo, desta forma, ser até mesmo deixada de lado. Aqui, não se trata de mergulhar nas complexas reflexões sobre a modernidade, sua origem, seu processo histórico nem sobre as transformações sofridas mais recentemente. Assim como já indicado para o termo nova evangelização, também no uso da literatura especializada sobre a modernidade é vasta e facilmente acessível. ${ }^{14}$ Importa perceber que a concepção de sujeito que se impôs foi a do ser voltado para si mesmo, concepção aplicada às mais diversas áreas da vida. $\mathrm{O}$ problema desta concepção manifesta-se no resultado final dos encontros entre os sujeitos. Se as individualidades valem enquanto individualidades, com a relacionalidade concebida como secundária, é inevitável que se chegue ao extremo do conflito. Assim como se afirma, na física, que dois corpos não ocupam o mesmo lugar, também na antropologia, dois sujeitos egocentrados, fechados em si, relacionais no máximo funcionalmente, tendem a preservar seus espaços, não hesitando inclusive em combater para tanto. Os resultados nós os vemos presentes no mundo atual. Atingem a totalidade da existência, fundamentando, mesmo que de modo implícito, agressões à vida, desde a concepção até a morte, desprezando populações inteiras e dilapidando o meioambiente. Exatamente porque, para este sujeito fechado em si, a existência do outro não é condição constitutiva, mas apenas decorrência, o Papa Francisco, em sua mensagem para a Quaresma de 2015, cunhou, a expressão "globalização da indiferença", enquanto caraterística do mundo atual.

A recordação desta realidade se dá como alerta para o fato de que a condição de sujeito não pode ser vista a partir da lógica egocentrada do conflito, na qual a busca por reconhecimento seria, no fundo, busca também de substituição ou supressão do outro, visto como oposto, a saber, o clero. Por certo, não se encontram documentos que abordem a questão sob esta ótica do conflito, ótica que poderia ser traduzida como lógica de contenda por espaço. Na prática, contudo, buscas de reconhecimento e respectivas reações correm o risco de se deixar guiar por tal lógica, mesmo que esta fundamentação não seja explícita. Acusações tanto de clericalização dos leigos quanto de subjugo por parte do clero e as explicações a respeito da vocação temporal do laicato podem, portanto, trazer consigo esta perspectiva de conflito, com base no sujeito fechado em torno de si mesmo. Em consequência, a atuação laical no mundo, por um lado, e a atuação intraeclesial pelo clero, por outro, se constituiriam numa espécie de tratado de paz.

\footnotetext{
${ }^{14}$ Por exemplo: MARCONDES, D. Iniciação à história da filosofia: dos pré-socráticos a Wittgenstein. Rio de Janeiro: Jorge Zahar, 2004.
} 
É, pois, para evitar esta concepção de sujeito própria da modernidade que o recente documento dos bispos do Brasil, apoiando-se na eclesiologia do Vaticano II, afirma que "na eclesiologia de comunhão funda-se a concepção dos cristãos leigos e leigas como sujeitos eclesiais" (DOC 105, 92). De fato, o que se tem convencionado chamar de eclesiologia de comunhão é a correspondência para a reflexão sobre a Igreja da condição antropológica que integra individualidade e relacionalidade. A partir do conceito de Povo de Deus, tão próprio do Concílio, ${ }^{15}$ afirma-se a importância de todos e de cada um. O elemento comum, que é a dignidade batismal, concretiza-se na diversidade de carismas, todos a serviço da única missão que é o anúncio do Reino de Deus. Assim como, antropologicamente, todo ser humano está relacionado a Deus, aos outros seres humanos e ao restante da criação, em termos eclesiológicos, os diferentes estados de vida encontram-se substancialmente referidos uns aos outros. Só nesta antropologia relacional vivenciada numa eclesiologia de comunhão é que se pode compreender a condição de sujeitos eclesiais para todos(as) os(as) batizados(as). Na base desta diversidade, manifesta-se, deste modo, a verdadeira igualdade já mencionada antes quanto à "dignidade e ação comum a todos os fiéis na edificação do Corpo de Cristo" (LG 32). Por isso, nunca é demasiado recordar que, anteriormente ao Vaticano II, a concepção partia da distinção para explicar a igualdade. O Concílio, revertendo a perspectiva sem, todavia, cair numa grosseira reversão dialética, afirmou a relacionalidade, partindo, para isso, da igualdade. Não se trata de mera reação pendular a uma prática pluricentenária de afirmação da distinção, mas de efetiva recuperação da identidade cristã enquanto unidade na diversidade. É, deste modo, uma específica eclesiologia que emerge do Concílio e somente por ela se pode compreender a ratificação da condição de sujeito eclesial para quem quer que seja, anteriormente a qualquer estado de vida.

Interessante observar como o Documento aqui estudado apresenta a condição de sujeito. O princípio da individualidade relacional se manifesta ao longo de todo o texto, mas se explicita no já mencionado capítulo 3, mais exatamente no item 3.1, com o inequívoco título "Liberdade, autonomia e relacionalidade" (DOC 105, 123SS). Tamanha a importância antropológica e eclesiológica destas três palavras que não seria ousado dizer que constituem um único termo expresso em três palavras ou, pelo menos, em duas, a saber, autonomia e relacionalidade. Deste modo, o cristão leigo ou leiga atua sempre

${ }^{15}$ LG 9-17, como recordado no documento da CNBB 94ss. 
em referência, ou seja, sempre em abertura fecunda, enriquecedora, dinâmica, intercambial, a Deus, aos outros e ao restante da criação. Esta perspectiva relacional da identidade humana, por ser constitutiva, não permite que uma realidade exista em si sem a outra. Ao contrário, para que uma possa existir, a(s) outra(s) deve(m) igualmente existir em igual condição de dignidade. Não há, portanto, como compreender a condição de sujeito reconhecida ao laicato se não for de modo relacional, isto é, na coexistência com outros estados de vida.

Em consequência, uma questão se torna inevitável a esta altura da reflexão. Se a eclesiologia decorrente do Vaticano II é tão clara, por que, há cinco décadas da conclusão daquele Concílio, ainda seja necessário produzir um Documento dos bispos de um país inteiro sobre o laicato como sujeito eclesial? A resposta é apresentada no referido Documento através da indicação de quatro entraves básicos ainda presentes na vida da Igreja (DOC 105, 133). Mais do que o detalhamento de cada um dos entraves, importa perceber que todos são descritos a partir da palavra oposição, a qual, seguindo a linha de raciocínio aqui exposta, nada mais é do que a concretização da lógica do ser fechado em si aplicada a algumas relações fundamentais, a saber: fé e vida, sagrado e profano, igreja e mundo, identidade eclesial e ecumenismo. A questão, portanto, que ainda motiva pronunciamentos ao estilo do Documento aqui estudado, encontra-se na permanência de uma mentalidade de oposição ou exclusão, que leva a atitudes que reduzem o andamento da missão evangelizadora e geram conflitos variados. Não fosse assim, o referido Documento não se teria construído a partir do prisma do sujeito eclesial, nem teria passado por um processo de maturação cronologicamente maior que outros. Porque, em outros momentos da história, afirmou-se mais a distinção, não há como deixar de reconhecer a existência de resquícios deste tipo de concepção no cotidiano pastoral de nossos dias. Por isso, embora clara a teoria teológica, a prática pastoral ainda manifesta dificuldades.

\section{O mundo e a Igreja como lugares de atuação do laicato}

Além das oposições mencionadas no Documento e de tantos outros resquícios históricos de práticas pastorais de oposição, há de se perguntar a respeito do lugar de atuação do laicato. A questão se concretiza, como bem sabemos, em dois âmbitos: o mundo e a Igreja. Possivelmente como decorrência de hábitos históricos, é possível deparar com uma discrepância quando se trata de compreender o espaço de atuação do laicato. De um lado, encontra-se a 
reiterada afirmação de que o lugar de atuação do laicato é no mundo, junto às realidades temporais, nos âmbitos, por exemplo, da ciência e da política, duas áreas bastante atingidas pelas transformações. De outro, a insistência por parte dos(as) leigos(as) acerca do trabalho ad intra por eles(as) realizado, e de maior espaço de participação e atuação. O Documento segue a tendência de indicar o mundo como o lugar de atuação laical. Citando a Lumen Gentium 2, o Documento, já em seus primeiros parágrafos, afirma categoricamente "a índole secular" que caracteriza o ser e o agir dos leigos e leigas (DOC 105, 5). Texto ainda mais claro é o $n^{\circ} 6$, transcrito da Evangelii Nuntiandi 70 :

Fiel à orientação conciliar sobre os leigos, o Beato Paulo VI lembra: “A sua primeira e imediata tarefa não é a instituição e o desenvolvimento da comunidade eclesial - esse é o papel específico dos pastores - mas sim (...) o vasto e complicado mundo da política, da realidade social e da economia, como também o da cultura, das ciências e das artes, da vida internacional, dos mass media e, ainda, outras realidades abertas à evangelização, como sejam o amor, a família, a educação das crianças e dos adolescentes, o trabalho profissional e o sofrimento". ${ }^{16}$

No entanto, na esteira do Documento de Aparecida, o Documento não deixa de reconhecer a importância da participação laical "na ação pastoral da Igreja" (DOC 105, 7; DAp 211). Este reconhecimento brota de um fato real e irrefutável, mencionado pelo Papa Francisco na Evangelii Gaudium 102, a saber, a constatação de que, na vida pastoral das comunidades, dos movimentos e demais associações, o laicato é não só numericamente bem maior que o clero como também vital para que as diversas atividades diretamente evangelizadoras aconteçam. De fato, o que seria de nossas comunidades, sem, por exemplo, o incansável trabalho das(os) catequistas? Quantas comunidades espalhadas por este Brasil afora sobrevivem exatamente por causa do trabalho dos(as) animadores(as) leigos(as)? ${ }^{17}$ Há, por conseguinte, um dado de fato que não nos permite compreender a indicação do mundo como negação da atividade laical também ad intra. Por isso, já em seu título o Documento indica que a ação do(a) leigo(a) é no mundo e na igreja, fora e dentro. Por certo, no decorrer dos parágrafos, aparecem reiterações a respeito da identidade $a d$

\footnotetext{
${ }^{16} \mathrm{EN}$, n. 70.

${ }^{17}$ Cf. DAp 99c: “... ministérios confiados aos leigos e outros serviços pastorais, como ministros da Palavra, animadores de assembleia e de pequenas comunidades..."
} 
extra. Este fato pode se explicar não apenas pelas características redacionais de um texto construído, ao final, por centenas de mãos, mas, acima de tudo, por uma preocupação grave e urgente, qual seja, a de ação ainda mais incisiva no mundo em vista de sua transformação, rumo à superação de realidades que agridem a dignidade humana e ofendem ao Criador (GS 27). A insistência na ação em meio ao mundo não pode ser concebida em chave de oposição, mas como preocupação pastoral em face a um fenômeno sempre presente na vida da Igreja e que pode estar ocorrendo nesta mudança de época. Trata-se da fuga para dentro da proteção eclesial em face de um mundo compreendido como caótico. É por isso que, já no título, o Documento recorda a condição de sal e fermento, para não permitir a acomodação no interior das comunidades como consequência do desprezo tácito pelas realidades temporais.

De fato, a problemática da fuga religiosa atinge índices preocupantes quando, para problemas de natureza secular, são dadas soluções exclusivamente religiosas. Diante de um povo, por exemplo, carente de atendimento de saúde, propostas religiosas voltadas para as curas imediatas tendem a se mostrar bastante atrativas, seja para os que as recebem, seja também para os que as geram. Os impactos de um mundo em transformação, com as sequelas da já mencionada globalização da indiferença, acabam funcionando como uma espécie de ímã na direção ad intra. Afinal, por que se comprometer pela transformação, se a solução é muito mais rápida no âmbito seguro e acolhedor da vida intracomunitária? O medo de um sal que não consegue salgar é a razão da insistência na atuação laical no mundo e não uma concepção eclesiológica de oposição (DOC 105, 39-40). Os serviços desenvolvidos pelos(as) leigos(as) no interior das comunidades podem e devem ser mantidos. Qualquer leitura na direção oposta, isto é, na linha de desvalorizar a ação interna do laicato, seria contraditória com a própria identidade cristã. A questão consiste em discernir caminhos para que, fazendo a experiência ad intra, o laicato transborde ad extra na construção do Reino de Deus.

\section{A específica atuação no mundo}

A partir do $\mathrm{n}^{\circ} 161$, o Documento indica qual deve ser a ação do(a) cristão(ã) leigo(a) no mundo. Na linha de uma das atuais urgências da ação evangelizadora da Igreja no Brasil, a saber, o serviço à vida plena de todos, ${ }^{18}$

\footnotetext{
${ }^{18}$ CNBB. Documento 102 - Diretrizes Gerais da Ação Evangelizadora da Igreja no Brasil para o período 2015-2019. Brasília: CNBB, 2015, n. 62ss.
} 
a missão no mundo é apresentada como um compromisso sociopolítico transformador, a serviço primordialmente dos pobres das periferias urbanas e do campo, que precisam sentir a proximidade de uma Igreja que socorre, defende e promove, sempre em vista de um mundo de crescentes justiça e paz. Em seguida, o Documento indica os caminhos e a base sobre a qual as ações dos(as) leigos(as) devem se desenvolver no mundo. Os caminhos são dois: o testemunho e a participação consciente e decisiva nos movimentos sociais, nas entidades de classe, partidos políticos, conselhos de políticas públicas, entre outros. A base é uma só: a Doutrina Social da Igreja (DOC 105, 162). Para cada um desses elementos, convém destacar atenção pastoral.

O testemunho individual, nas mudanças de época, quando as tradições e instituições perdem muito de sua força, ganha boa dose de amplitude. $\mathrm{O}$ que antes aqui já se mencionava a respeito do clérigo que se impõe não tanto pela instituição que representa, porém muito mais pelo carisma diferenciado que manifesta, vale também para os(as) leigos(as). O pluralismo, no caso aquele que atinge o mundo religioso, enfraquece as identidades manifestadas primordialmente a partir do institucional e do tradicional. Já não basta aos leigos inseridos num mundo complexo e em acelerada mutação afirmar-se como membros desta ou daquela instituição e desejar que a aceitação de suas opções e posturas ocorra como consequência deste fato. $\mathrm{O}$ distanciamento das identidades fixadas, fenômeno tão conhecido como liquefação, ${ }^{19}$ coloca os leigos num contínuo embate com diferentes formas de crer e suas consequências éticas. Trata-se de um período histórico em que, a todo o tempo, é preciso justificar-se, apresentando os motivos das opções feitas em cada aspecto concreto. Esta realidade se torna ainda mais aguda na medida em que as religiões experimentam, umas mais, outras menos, grande carga de diversidade interna no modo de crer e praticar o que se crê. Isto ocorre também no catolicismo. Se, portanto, desaparecem os apoios ao indivíduo, o que lhe sobra se não a si mesmo, como um indivíduo solto no ar diante de muitas possibilidades e interpelações?

Esta individualização dos valores e das crenças apresenta uma ambiguidade que não pode ser desconsiderada. Por um lado, é positiva enquanto pede de cada indivíduo a manifestação pessoal, livre e consciente. Por outro, no entanto, exatamente por estar ligada a um forte processo de fragilização, corre o risco de largar o indivíduo nas garras da perspectiva da modernidade,

${ }^{19}$ Cf. BAUMAN, Z. O Mal-Estar da Pós Modernidade. Rio de Janeiro: Zahar, 1998, p. 30. 
com a tão citada lógica da oposição, cujo resultado final é o conflito. É por isso que, por exemplo, se assiste nestes tempos atuais a fechamentos em posturas com odor fundamentalista, incapazes que são de dialogar e compreender pontos de vista diferentes. As consequências sobre a missão do(a) leigo(a) no mundo são, então, facilmente compreendidas. $\mathrm{O}$ (a) leigo(a) não quer ser apenas um emissário categorizado da hierarquia junto às realidades temporais e o Documento 105, na linha do pensamento do Vaticano II, assim ratifica (DOC 105, 8). Tampouco, porém, pode o(a) leigo(a) deixar-se enredar nas armadilhas do dualismo que separa a relação com a Igreja da relação com o mundo, caso em que a ação dos(as) leigos(as), nos casos mais extremos, nada teria que ver com o que a Igreja indica. Confusos(as) diante de uma realidade altamente plural, os(as) leigos(as) correm o risco de se proteger através ou da separação abissal ou da junção absoluta. No primeiro caso, restringem a fé à vivência intraeclesial, atuando nos diversos setores seculares a partir de outras motivações, que não o Evangelho e, mais especificamente, a Doutrina Social da Igreja. Neste caso, um(a) leigo(a) poderá ser internamente catequista e, no ambiente sociotransformador, membro de uma associação cujos princípios e práticas destoem dos ensinamentos da Igreja. No segundo caso, o laicato poderá se organizar a partir de associações cujo rosto é notadamente religioso, ao estilo das bancadas políticas atuais no Brasil. Para estas, a organização baseada em partidos políticos é uma realidade apenas formal, pois o que realmente conduz o processo é a questão religiosa, com a consequente luta por interesses das respectivas instituições, talvez mais do que pelo bem comum e a atenção aos pobres e sofredores. ${ }^{20}$ Por tudo isso, haverá de se considerar cada vez mais, no ritmo em que a mudança de época caminha, a importância do testemunho pessoal.

O Doc 105 menciona explicitamente o testemunho 27 vezes. Alegra-se pela história da atuação laical no Brasil e indica reiteradamente o testemunho como caminho para a missão evangelizadora. Uma rápida passada de olhos no documento permitirá localizar as referências. Importa não esquecer que o

\footnotetext{
${ }^{20}$ Nota da CNBB sobre o momento. Na mesma assembleia dos bispos em que o Documento 105 foi aprovado, os bispos também emitiram uma nota sobre o atual momento brasileiro. Ali se lê que "Importante se faz reafirmar que qualquer solução que atenda à lógica do mercado e aos interesses partidários antes que às necessidades do povo, especialmente dos mais pobres, nega a ética e se desvia do caminho da justiça". Cf. CNBB. "Declaração sobre o momento nacional”. Disponível em: http://www.cnbb.org.br/index.php?option=com_content\&view=article\&id=18559: $\mathrm{cnbb}$-divulga-declaracao-sobre-o-momento-nacional\&catid=450\&Itemid= 263 . Acesso em 09 de maio de 2016.
} 
momento histórico atual jogou nas costas de cada leigo(a) um peso que ele(a), em outros momentos históricos, não necessitava carregar, isto é, o peso do testemunho pessoal. Este peso se manifesta muitas vezes já no seio familiar, onde o pluralismo cultural, ético e religioso se faz presente com significativo vigor. Em determinadas situações, o(a) leigo(a) é o único(a) a seguir Jesus Cristo, a ter vida eclesial e a trabalhar pelos valores do Reino de Deus. Como, então, fazer? Como, por exemplo, manter sua fé e as atitudes decorrentes diante da pressão do sangue familiar por seguir outros caminhos? Onde haverá de se apoiar, se a sensação é de solidão existencial e abandono em meio à diversidade?

Esta questão se desdobra também para os diversos âmbitos seculares. Vai, por exemplo, para o local de trabalho, onde decisões precisam ser tomadas a partir de exigências éticas que nem sempre, na referida solidão existencial, se manifestam claras e tranquilas. Atinge, num terceiro exemplo, o mundo das opções e participações políticas, em que é preciso se integrar a associações cujos princípios nem sempre se coadunam com o que a Igreja ensina e com o que às pessoas ao redor compreendem como ensinamento da Igreja. Como fica um(a) leigo(a) que se aventura no mundo específico da política partidária? A quem deve seguir: sua consciência, as indicações da hierarquia para os assuntos concretos ou a decisão do partido? O que fazer quando as decisões do partido destoam diametralmente dos ensinamentos da Igreja? A quem seguir se a consciência, mesmo anteriormente bem formada, se depara com tamanho bombardeio que só vê a opção de separar dualisticamente as realidades e se unir em bancada religiosa ou fechar com o partido? Ao mesmo tempo em que alerta para a responsabilidade sociopolítico transformadora do(a) leigo(a), cobrandolhe uma inegável atuação e lhe alertando para o pecado do escapismo, a Igreja não pode deixar de oferecer algo que sustente a consciência, respeitando, por certo, a autonomia desta mesma consciência, como tantas vezes destaca o Doc. 105. É neste sentido que se acolhe a contundente crítica que o Papa Francisco faz ao modo como se diminui, subestima ou mesmo se anula a participação laical. Para o Papa, ao se esquecer da dignidade que brota da graça batismal, a postura clericalista tem como consequência, o esmaecimento e até a anulação do profetismo a que os(as) leigos(as) são chamados(as). ${ }^{21}$

\footnotetext{
${ }^{21}$ FRANCISCO. "Carta ao Cardeal Marc Ouelet, Presidente da Pontifícia Comissão para a América Latina", 19 de março de 2016. Disponível em: http://w2.vatican.va/content/francesco/ pt/letters/2016/documents/papa-francesco_20160319_pont-comm-america-latina.html. Acesso em 09 de maio de 2016.
} 


\section{A formação para a missão no mundo}

Sobre a temática da formação da consciência, o referido documento alerta para o caráter insipiente do que é oferecido aos(às) leigos(as), alertando para o que chama de "amadorismo" em alguns processos formativos (DOC 105, 47). A superação de tal estado das coisas se dará na medida em que, ainda de acordo com o Doc 105, na linha de Aparecida, se fortalece a consciência de cada leigo(a) como discípulo(a) missionário(a) de Jesus Cristo, situação que "contempla a conversão pessoal, o discipulado, a experiência comunitária, a formação bíblico-teológica e o compromisso missionário" (DOC 105, 188). $\mathrm{O}$ que se tem aqui encontra-se em direta conexão com as urgências da ação evangelizadora da Igreja no Brasil, porque tanto as Diretrizes Gerais da Ação Evangelizadora quanto o Documento 105 nasceram do mesmo contexto de mudança de época, o qual deve ser enfrentado com a acima mencionada nova evangelização. No entanto, um ponto merece destaque neste processo formativo. Se, por um lado, o Documento 105 insiste bastante no esmero pelos mecanismos de formação (DOC 105, 147), por outro, não deixa de recordar que é exatamente na experiência eclesial que ocorre a verdadeira e profunda formação (DOC $105,234)$. Na medida em que não existe ruptura, mas relação entre o que é vivenciado no mundo e na Igreja, a experiência eclesial precisa necessariamente ser capaz de possibilitar, primeiramente, relacionamentos humanos primários diferentes dos conflitos e das competições muitas vezes encontradas ad extra. A metáfora do oásis no meio do deserto pode ser aqui aplicada no sentido de que a base para qualquer formação dos(as) leigos(as) haverá de ser sempre o que se experiencia na comunidade eclesial. Cursos, palestras, simpósios e similares são importantes e ajudarão na medida, entretanto, que tiverem como base uma experiência de Igreja onde a marca distintiva se encontra na fraternidade dos irmãos que se apoiam, se perdoam e se socorrem. Não se trata de negar que esta experiência possa ocorrer em outros âmbitos extracomunitários. O desafio aqui é que ela ocorra nas comunidades eclesiais como seu distintivo.

Por isso, angustia tanto que, para boa parcela dos(as) batizados(as), o que se ofereça seja ainda o modelo eclesial da prestação de serviços. Já Aparecida, há praticamente dez anos atrás, chamava a atenção para este fato. ${ }^{22}$ São paróquias territorialmente extensas, com público diversificado, ação pastoral centralizada na igreja matriz e em algumas capelas, com predominância para

22 Por exemplo, DAp 172-173 e 304-305. 
celebrações de massa. É preciso reconhecer que uma experiência eclesial organizada a partir deste paradigma não ajuda na formação da consciência. Foi por esta razão que a Igreja no Brasil, em outro documento que seguiu o mesmo itinerário do que aqui é estudado, se manifestou a respeito das pequenas comunidades $^{23}$ e o Doc. 105, citando Aparecida 308, assim se pronunciou:

"As pequenas comunidades eclesiais, como recorda o Documento de Aparecida, são um ambiente propício para escutar a Palavra de Deus, para viver a fraternidade, para animar na oração, para aprofundar processos de formação na fé e para fortalecer o exigente compromisso de ser apóstolos na sociedade de hoje. São lugares de experiência cristã e evangelização que, em meio à situação cultural que nos afeta, secularizada e hostil à Igreja, se fazem muito mais necessários". (DOC 105, 147)

Em resumo, o protagonismo laical no mundo, conforme a identidade cristã indica e a realidade atual transforma em urgência, depende diretamente do modo como a Igreja internamente se vai estruturar. ${ }^{24}$ São dois processos que precisam ser vivenciados de modo concomitante: o processo externo, através da presença do laicato como sujeito eclesial, e o processo interno, através da reconfiguração da dinâmica comunitária, onde o laicato também encontra sua condição de sujeito eclesial.

Interessante observar a diferença que existe entre o clero e o laicato quando se trata de viver nos dois âmbitos, o ad intra e o ad extra. Os leigos têm a graça e o dever de binar, isto é, de atuar nos dois espaços. Os clérigos, por vocação e missão, recolhem-se, esvaziam-se da possibilidade de agir no mundo, para exatamente dar espaço a que os leigos o façam. Pela formação e pela eventual disponibilidade de tempo, os clérigos até poderiam agir também no mundo, de modo mais direto, mais incisivo. Como, no entanto, agem como sinais do Deus-Comunhão, que, por amor, se esvazia para dar espaço ao outro, no caso, ao laicato, os clérigos, ao assim se tornarem, abrem mão de agir mais diretamente nas atividades temporais. Servem ao mundo, servindo àqueles(as) que atuam no mundo.

\footnotetext{
${ }^{23}$ Documentos da CNBB 100 - Comunidade de comunidades: uma nova paróquia. A conversão pastoral da paróquia. Brasília: CNBB, 2012.

${ }^{24}$ Sobre os processos de reconfiguração da experiência eclesial, notadamente nos grandes centros urbanos, ver: AMADO, J. P. "Jesus Cristo e o diálogo com as culturas urbanas". In: PIVA, Elói Dionísio (Org.). Evangelização: legado e perspectivas na América Latina e no Caribe. Petrópolis: Vozes, 2007, pp. 253-281.
} 


\section{A missão do laicato na Igreja}

Uma experiência eclesial integrada implica necessariamente a vida de comunidade. $\mathrm{O}$ acesso a Deus passa pela mediação dos irmãos e irmãs e esta mediação tem que, também de modo indispensável, se concretizar em relacionamentos humanos primários. É por isso que a rede ou comunidade de pequenas comunidades, territoriais ou ambientais, é indispensável para a concretização do sujeito eclesial. O Doc. 105 trata deste âmbito a partir do número 136, iniciando pelo destaque à família como primeiro espaço para a vivência eclesial, exatamente por causa dos laços humanos mais profundos ali experimentados e marcantes para o resto da vida.

De fato, o anúncio do Deus-Trindade, do Deus-Comunhão, implica que se viva, que se experiencie uma comunhão que, no dizer bíblico, transcenda até mesmo os laços de sangue (Lc 8,20-21; 11,27-28). Um Deus exclusivamente monoteísta, sem a dimensão trinitária, acaba por conduzir a um ser humano egocentrado, conforme já antes comentado. O Deus da Revelação se manifestou como um mistério de amor includente, como gratuidade que gera comunhão e convida à comunhão. É comunidade relacional, que se auto esvazia por amor ao diferente, isto é, às criaturas. Deste modo, a comunhão entre as pessoas não é uma exigência do momento histórico caótico, de crise estrutural, de mudança de época. Ela vale para todos os tempos e contextos. A comunhão é, reiterando o pensamento, um dado antropológico e, consequentemente, eclesiológico, cuja origem é teo-lógica, isto é, remete ao Deus da Revelação. Dito de modo simples, a salvação trazida por Jesus Cristo implica na ruptura com uma vida não relacional, egocentrada e no ingresso em uma vida de crescente comunhão, com participação no viver dos(as) outros(as) irmãos(ãs) e, conforme a atual consciência evangelizadora, também do restante da criação. É a koinonia de vida, onde dons e bens são efetivamente colocados a serviço porque o mais importante é a existência das demais pessoas e o vínculo que as une. Esta é a razão pela qual preocupa tanto experiências eclesiais marcadas mais pela prestação de serviços do que pela comunhão de vida. Daí a necessidade, transformada em urgência pelas Diretrizes da Ação Evangelizadora da Igreja no Brasil, de se traduzir esta condição teológica em estruturas, em configurações que permitam, a partir da vivência, interpelar a individualização excludente, o consumismo dilapidante e a indiferença globalizada. A interpelação brota não de discursos, mas de uma prática capaz de superar qualquer entrave e mostrar experiencialmente aos(às) leigos(as) 
que agem no mundo que a lógica de lutas, trapaças, corrupção, desrespeito, indiferença e tramoias, por maior que esta lógica seja quantitativamente, ela não tem a força qualitativa da vida de comunidade. Se um(a) leigo(a) se vê rodeado por discursos e, mais grave ainda, por práticas de exclusão, poderá afirmar que a comunhão e tudo que dela decorre são viáveis exatamente porque ele(a) assim vivencia na comunidade. É, pois, neste sentido, que a missão ad extra implica a reconfiguração ad intra.

Por sua vez, a reconfiguração ad intra não se restringe apenas às comunidades enquanto tais. Abrange também os serviços e ministérios, de modo que a rede de que tanto se vem falando desde Santo Domingo (SD $58,142)$ diz respeito, no sentido mais completo do termo reconfiguração, às comunidades, aos serviços e aos ministérios, permitindo, deste modo, que os(as) leigos(as) sejam também internamente sujeitos eclesiais. O Documento traz à cena as paróquias e os movimentos, as novas comunidades e outras formas de associação, indicando que todas precisam estar em relação através da chamada pastoral de conjunto (DOC 105, 139). Fala em seguida dos organismos de participação, isto é, dos conselhos e das assembleias (DOC 105 141-145), como instâncias onde a voz do laicato é acolhida. Trata-se de uma experiência eclesial que efetivamente corresponda à vocação de local privilegiado para a manifestação dos diversos dons e carismas, manifestação esta que se torna sacramental para o mundo. Deste modo, o primeiro serviço que a Igreja, em seu conjunto, na diversidade de modos de vida, é chamada a prestar é o de testemunhadora visível da comunhão do Deus Invisível. A condição de sinal da salvação impele a Igreja a continuamente buscar formas novas de viver e manifestar esta comunhão radical e escatológica, que começa no hoje, mas só se completa na eternidade e, por isso mesmo, é busca contínua, revisão constante. As comunidades cristãs se deparam, consequentemente, diante do imperativo de se tornarem cada vez mais espaços de fermentação dos carismas semeados pelo Espírito, numa comunhão que os olhos marcados pelo fechamento egocêntrico não podem compreender.

Vários destes serviços ou ministérios leigos foram mencionados por Aparecida (DAp 99c, 209-215). Alguns já estão historicamente sedimentados, como é o caso do serviço de catequista, ainda que a crescente sensibilidade para a iniciação à vida cristã reposicione determinados aspectos. Também os serviços de visita, seja sazonal seja contínua, aos doentes, aos presos e a outras formas de sofredores, bem como a áreas distantes dos prédios eclesiais, já se sedimentaram na vida das Igrejas locais. O acompanhamento, por 
exemplo, dos enfermos, através de atividades ligadas à saúde e atendimento eucarístico doméstico já são igualmente presença solidificada em todo o país. Nestes exemplos e em muitos outros, pode-se repetir o que já foi dito antes: o número de leigos(as) atuando nas comunidades é não só maior que o clero e os consagrados, como também traz uma contribuição insubstituível para a riqueza da comunhão.

Sem esta reconfiguração que busca a rede de comunidades, mas também de serviços e ministérios, a comunhão corre o risco de perder sua visibilidade, esvaziando-se pastoralmente de sua dimensão sacramental. A Igreja, enquanto realidade teológica, não perde sua condição sacramental, que é garantida pela graça de Deus. A condição sacramental, entretanto, se desbota pastoralmente se não for inteligível para as pessoas que estão na Igreja e para o mundo ao qual a Igreja é chamada a servir. Por isso, a importância de estruturas de relacionamento humano primário, mas também de atuação e participação dos(as) fiéis leigos(as), como uma decorrência da condição de batizados(as). Interessante observar que o Papa João Paulo II, ao orientar a Igreja para o ingresso no então novo milênio, apresentava a necessidade de novas expressões de comunhão ${ }^{25}$ aptas a revelar à humanidade do terceiro milênio o mistério da comunhão como característica fundamental a toda a vida. Estas novas formas precisam expressar a comum responsabilidade de todo o povo de Deus, em seus diversos modos de vida, numa contínua busca do sentir e do agir em comum, na consciência de uma missão que é sempre maior que qualquer carisma e que, por isso mesmo, chama à soma, à integração.

Neste sentido, o desafio a respeito de novas estruturas de comunhão impele a redescobrir formas colegiais ou sinodais de participação, as quais, em profunda comunhão com o ministério hierárquico, manifestam a identidade mais original da Igreja. Trata-se de, mais uma vez na história da Igreja, se (re)descobrir formas de vivenciar a corresponsabilidade de todos os membros de uma comunidade e das comunidades entre si. É a concretização da atitude de escuta do Espírito, que se manifesta na diversidade reunida, em fidelidade à mensagem do relato bíblico de Pentecostes (At 2,1-11). Esta escuta do Espírito se concretiza na escuta mútua, no contemplar o diferente e acolher sua contribuição, numa atitude de crescente diálogo e participação dos diversos modos de vida, buscando-se o consenso desde as pequenas decisões até as maiores, ainda que experimentando percalços neste caminhar. De

${ }_{25}$ JOÃO PAULO II. Carta Apostólica Novo Millennio Ineunte, 44. 
fato, a beleza da Igreja se manifesta de modo bastante claro quando se deixa emergir a articulação equilibrada entre as diversidades, quando se concretiza o acolhimento de pessoas com distintas formas de compreensão. Nesse sentido, para que a comunhão não se torne um ideal que levita no ar, mas que, no seguimento de Jesus Cristo encarnado, desce até o chão do cotidiano eclesial, algumas atitudes devem ser consideradas.

A primeira delas consiste em fazer da comunhão uma forte referência das diversas formas de espiritualidade. Diante do fenômeno de um laicato que crescentemente se organiza nas chamadas novas comunidades, cada uma com seu carisma, sua história e sua missão, o elemento comum haverá de ser, como, aliás, sempre foi, a eclesialidade, esta entendida também como abertura aos demais carismas e, portanto, como comunhão. Em segundo lugar, não se alimenta a comunhão se não existirem espaços concretos para isso. São os já tão referidos ambientes para relacionamentos humanos primários e são também os espaços de participação e decisão. Neste último caso, tendo em vista o horizonte escatológico que sempre chama para adiante, impedindo a acomodação, importa continuamente encontrar caminhos para o equilíbrio entre as dimensões consultiva e deliberativa dos organismos eclesiais. A Igreja não é nem monarquia, ao estilo de um único sujeito eclesial, nem é democracia ao estilo das decisões tomadas pela maioria sem que sejam considerados também os argumentos da minoria numérica. A Igreja-comunhão é colegialidade no sentido de que deve, à exaustão, ouvir e dialogar sempre mais até que se possa dizer que se ouviu a voz do Espírito que falou entre irmãos(ãs) e pelos(as) irmãos(ãs), falando pelos que tiveram sua sugestão acolhida, pelos que tiveram sua sugestão rejeitada e pelos que tiveram sua sugestão transformada. $\mathrm{Na}$ verdade, a eclesialidade não se manifestou apenas no assunto debatido, que pode ter sido sobre detalhes profundamente secundários. Manifestou-se bem mais na forma como o assunto foi enfrentado, ou seja, na forma de comunhão e de colegialidade. Só assim os conflitos internos das comunidades eclesiais serão efetivamente superados, pois através da abertura de espaço para falar e ouvir, cresce o ambiente de confiança mútua, condição indispensável para que se ouça o Espírito que sempre fala, mas nem sempre é ouvido. Com isso, não se anula o exercício da autoridade pastoral na Igreja, mas se reconfigura, como tantas vezes ao longo da história da Igreja já se fez. E, assim, os(as) leigos(as), sujeitos ad intra, se fortalecem, vivenciam a formação permanente, para serem igualmente sujeitos eclesiais ad extra. 


\section{O laicato e a missão inculturadora}

Certamente, há de se destacar o histórico papel do laicato na ação missionária, em especial na missão ad gentes, seja na parte da defesa e da promoção do ser humano, com ações nos campos da saúde e da educação, seja no que diz respeito à explícita atividade evangelizadora. Nas últimas décadas, com o fenômeno das novas comunidades, tem-se assistido a leigos(as) que concretizam sua consagração exatamente na missão a outras terras. Sendo celibatários ou como casais que envolvem os filhos na escolha feita, vivem a dimensão missionária, concretizando mais uma possibilidade da condição de sujeito eclesial. No entanto, é preciso ir um pouco mais além na reflexão e perceber o laicato, simplesmente enquanto tal, como uma condição essencialmente missionária, riqueza para a Igreja, mesmo que não execute a missão ad gentes como aqui exemplificada. Há no DNA da condição laica uma perspectiva missionária irrenunciável. Trata-se da capacidade de atuar na inculturação do Evangelho.

$\mathrm{O}$ Doc. 105 se refere uma única vez à inculturação. Quando indica as condições para a formação do laicato, o documento coloca dentre as condições de maturidade a perspectiva de inculturação (DOC 105, 236). Esta última referência dentro das considerações do laicato como sujeito eclesial é importante porque firma o caminho pelo qual a ação missionária deve ser considerada. A um ser humano fechado em si, corresponde uma experiência de Igreja com baixos teores de comunhão e uma perspectiva missionária unidirecional, ou seja, aquela concepção de missão que, confundindo conteúdo e forma, age em caminho de mão única. Ao contrário, a um ser humano concebido relacionalmente, corresponde uma eclesiologia de comunhão e, em consequência, uma perspectiva missionária em chave inculturadora, onde a relação da Igreja com o mundo é, ao mesmo tempo, de escuta e de fala. A Igreja fala do Evangelho, mas ela o faz através da escuta das situações concretas de cada pessoa e de cada povo. Esta foi a consciência evangelizadora do Vaticano II ao articular as alegrias e as esperanças dos discípulos de Cristo com as alegrias e as esperanças das pessoas de nosso tempo (GS 1).

A experiência cristã é, de algum modo, a contínua busca por uma nova linguagem. $\mathrm{O}$ anúncio do Ressuscitado impele à comunhão. Por ser uma realidade que transcende as compreensões humanas, por ser uma mensagem que ultrapassa os limites do mensurável, este anúncio só pode ser realizado, isto é, vivenciado, transmitido e acolhido, a partir da comunhão de vida, 
alimentada pelo contínuo diálogo e pela confiança recíproca. Não se trata de uma linguagem que parte da necessidade de explicações racionais, de lógicas interpretativas, mas de uma dinâmica vivencial, linguagem que, sob o impulso do Espírito, não precisa, no primeiro momento, de tradução para categorias racionais. Primeiro, deve vir a experiência de irmãos e irmãs. Depois, o detalhamento racional. Somente nesta perspectiva é que a missão poderá ser realmente cumprida por sujeitos eclesiais relacionais, numa IgrejaComunhão. Emerge, assim, a importância missionária do laicato como sujeito eclesial. Por estar no mundo, o(a) leigo(a) conhece as alegrias, as esperanças, as dores e as concretizações deste mesmo mundo. Conhece as estruturas de pensamento e as condições interpretativas. Conhece "os critérios de julgar, os valores que contam, os centros de interesse, as linhas de pensamento, as fontes inspiradoras e os modelos de vida". ${ }^{26}$ São os(as) leigos(as) que permitem, com o seu vai-e-vem entre o mundo e a Igreja, que a ação missionária não se torne acomodada, monologal, girando em torno de si mesma, afastada da vida de pessoas e povos, numa espécie de idioma técnico desconhecido dos interlocutores. Na vivência do duplo espaço Igreja e mundo, os(as) leigos(as) têm diante de si uma grande riqueza pneumatológica, pois permitem à Igreja falar, se assim se pode dizer, uma língua diferente das cotidianas, porque é a língua da comunhão de vida, a qual, por isso mesmo, é compreensível por todos(as).

\section{Conclusão: Um desafio em meio a vários desafios}

Em sua carta ao Presidente da Pontifícia Comissão para a América Latina, o Papa Francisco recorda a expressão tantas e tantas vezes utilizada nas décadas posteriores ao Vaticano II: "Chegou a hora dos leigos". Para, contudo, alertar a Igreja, o Papa afirma que "parece que o relógio parou". Trata-se de uma advertência grave a respeito da lentidão com que determinados processos de transformação necessitam ser assumidos para que se responda evangelicamente aos desafios do tempo atual. Dentre estes desafios, a Igreja no Brasil destacou, na última assembleia dos bispos, o laicato como sujeito eclesial. Através de um processo de maturação, o documento final chega agora aos seus destinatários maiores: os(as) próprios(as) leigos(as). Não se nega que a questão seja complexa, com resquícios históricos e teológicos,

\footnotetext{
${ }^{26}$ PAULO VI. Evangelii Nuntiandi, 19.
} 
estes nos campos da antropologia teológica e da eclesiologia. Reconhecese que a complexidade está diretamente relacionada à urgência e ao modo com que as questões devem ser tratadas. A condição de urgente já vem sendo indicada desde 2011 pelas Diretrizes Gerais da Ação Evangelizadora da Igreja no Brasil. O modo articulado de solução também vem indicado pelas mesmas Diretrizes e pela realidade que se apresenta diante de todos(as). O mundo atual clama de dores que pedem soluções inadiáveis ${ }^{27}$ e conjuntas. É preciso praticar uma antropologia mais relacional numa igreja consequentemente mais comunional, com um laicato efetivamente sujeito das ações missionárias na Igreja e no mundo. O Documento 105 é mais abrangente que os enfoques aqui apresentados, permitindo outras reflexões que ajudem a cumprir o que o atual momento histórico trouxe para os primeiros lugares da preocupação evangelizadora.

\section{Referências bibliográficas}

ALBERIGO, G. Storia del Concilio Vaticano II. Bologna: Peeters, Leuven \& Il Mulino, 2012.

AMADO, J. P. "Realmente livres? A ambiguidade antropológica dos ambientes urbanos". In: RUBIO, A. G. O humano integrado. Abordagens de antropologia teológica. Petrópolis: Vozes, 2007, pp. 23-46.

AMADO, J. P. "Jesus Cristo e o diálogo com as culturas urbanas". In: Elói Dionísio Piva. (Org.). Evangelização: legado e perspectivas na América Latina e no Caribe. Petrópolis: Vozes, 2007, pp. 253-281.

ANTON, A. "Lo sviluppo della dotrina sulla Chiesa nella teologia dal Vaticano I al Vaticano II". In: ANTON, A. L'ecclesiologia dal Vaticano I al Vaticano II. Bréscia: La Scuola, 1973, pp. 27-86.

ASTIGUETA, D. G. La noción de laico desde el Concilio Vaticano II al CIC 83. El laico: sacramento de la Iglesia y del mundo. Roma: Gregoriana, 1999.

BAUMAN, Z. O Mal-Estar da Pós Modernidade. Rio de Janeiro: Zahar, 1998.

CHENU, M. D. Pour une théologie du travail. Paris: Seuil, 1955.

CONCÍLIO VATICANO II. "Constituição Dogmática Lumen Gentium

${ }^{27}$ FRANCISCO. Enciclica Laudato Si', 53. 
sobre a Igreja", 21 de novembro de 1964. Disponível em: <http://www. vatican.va/archive/hist_councils/ii_vatican_council/documents/vat-ii_ const_19641121_lumen-gentium_po.html >. Acesso em 09 de maio de 2016.

CONCÍLIO VATICANO II. "Constituição Pastoral Gaudium et Spes sobre a Igreja no mundo atual", 7 de dezembro de 1965. Disponível em: $<$ http:// www.vatican.va/archive/hist_councils/ii_vatican_council/documents/ vat-ii_const_19651207_gaudium-et-spes_po.html>. Acesso em 09 de maio de 2016.

CONFERÊNCIA NACIONAL DOS BISOS DO BRASIL - CNBB. Cristãos leigos e leigas na sociedade: sal da terra e luz do mundo. Documentos da CNBB 105. Brasília: CNBB, 2016.

CONGAR, Y. Jalons pour une théologie du laicat. Paris: Cerf, 1953.

CONSELHO EPISCOPAL LATINO-AMERICANO - CELAM. Texto conclusivo da V Conferência Geral do Episcopado Latino-Americano e do Caribe. Documento de Aparecida. Brasília/São Paulo: CNBB/Paulus/ Paulinas, 2007.

DANIÉLOU, J. Essai sur le mystère de l'histoire. Paris: Seuil, 1953.

DUQUE, A. D. La nueva evangelización. Itinerario, Identidady Características a partir del Magisterio Episcopal Latinoamericano. Bogotá: CELAM, 2012.

FISICHELLA, R. La Nuova Evangelizzazione. Una sfida per uscire dall'indifereza. Padova: Mondatori, 2011.

FISICHELLA, R. "La nueva evangelización a la luz del Magisterio Pontificio". In: PONTIFICIA COMISIÓN PARA AMERICA LATINA. Reflexiones sobre la nueva evangelización em América Latina. Desafios y Prioridades. Vaticano: CAL, 2012, pp. 15-30.

FRANCISCO. "Exortação Apostólica Evangelii Gaudium”, 24 de novembro de 2013. Disponível em: $<$ http://w2.vatican.va/content/francesco/pt/apost exhortations/documents/papa-francesco_esortazione-ap_20131124_ evangelii-gaudium.html $>$. Acesso em 09 de maio de 2016.

KASPER, W. Theologie und Kirche. Mainz: Matthias-Grünewald-Verlag, 1987. 
MADRIGAL, S. "Las relaciones Iglesia-Mundo según el Concilio Vaticano II”. In: BILBAO, G. U. (Edit). Teología y Nueva Evangelización. MadriParis: Comillas-Desclée de Brower, 2005, pp. 13-96.

MARCONDES, D. Iniciação à história da filosofia: dos pré-socráticos a Wittgenstein. Rio de Janeiro: Jorge Zahar, 2004.

Militello, C. (Coord.). Os leigos depois do Concílio. A identidade e a missão dos cristãos. Prior Velho: Paulinas, 2012.

NAVARRO, L; PUIG, F. (Cur). Il fedele laico. Realtà e prospettive. Milano: Giuffre, 2012.

PAULO VI. "Exortação Apostólica Evangelii Nuntiandi”, 8 de dezembro de 1975. Disponível em: <http://w2.vatican.va/content/paul-vi/pt/apost_ exhortations/documents/hf_p-vi_exh_19751208_evangelii-nuntiandi. html 09/05/2016>. Acesso em 09 de maio de 2016.

PINHEIRO, J. E.; ALVES, A. A. Os cristãos leigos no mundo da política à luz do Concílio Vaticano II. Petrópolis: Vozes, 2013.

RUBIO, A. G. (Org.). O humano integrado. Abordagens de Antropologia Teológica. Petrópolis: Vozes, 2007.

TURBANTI, G. "A autonomia dos leigos da Lumen Gentium à Gaudium et Spes". In: MiLitello, C. (Coord). Os leigos depois do Concílio. A identidade e a missão dos cristãos. Lisboa: Paulinas, 2012, pp. 12-13.

ZANETTI, E. La nozione di laico nel dibattito preconciliare. Alle radici di una svolta significativa e problemática. Roma: PUG, 1998.

Joel Portella Amado

Doutor em Teologia Sistemático Pastoral pela Pontifícia Universidade Católica do Rio de Janeiro Professor na Pontifícia Universidade Católica do Rio de Janeiro

Rio de Janeiro / RJ - Brasil E-mail: joelamado@puc-rio.br

Recebido em: 05/05/16

Aprovado em: 31/05/16 